\title{
Low microbial biomass within the reproductive tract of mid-lactation dairy cows: A study approach
}

\author{
L. Lietaer, ${ }^{1}$ O. Bogado Pascottini, ${ }^{1,2}$ E. Hernandez-Sanabria, ${ }^{3}$ F.-M. Kerckhof, ${ }^{4}$ T. Lacoere, ${ }^{4}$ N. Boon, ${ }^{4}$ \\ L. Vlaminck, ${ }^{5}$ G. Opsomer, ${ }^{1 *}$ and T. Van de Wiele ${ }^{4}$ \\ ${ }^{1}$ Department of Reproduction, Obstetrics and Herd Health, Faculty of Veterinary Medicine, Ghent University, Merelbeke, Belgium[AU1: Provide \\ postal codes for all affiliations] \\ ${ }^{2}$ Department of Veterinary Sciences, Laboratory of Veterinary Physiology and Biochemistry, University of Antwerp, Wilrijk, Belgium \\ ${ }^{3}$ Department of Microbiology and Immunology, Laboratory of Molecular Bacteriology, Rega Institute, KU Leuven, Leuven, Belgium \\ ${ }^{4}$ Department of Biotechnology, Faculty of Bioscience Engineering, Center for Microbial Ecology and Technology (CMET), Ghent University, Ghent, \\ Belgium \\ ${ }^{5}$ Department of Surgery and Anaesthesiology of Domestic Animals, Faculty of Veterinary Medicine, Ghent University, Merelbeke, Belgium
}

\begin{abstract}
The microbiome from the reproductive tract is being investigated for its putative effect on fertility, embryo development, and health status of the human or animal host postpartum. Besides the presence of a vaginal microbiome, recent studies have claimed the existence and putative role of the uterine microbiome. Yet, the extremely low bacterial numbers and high eukaryotic/ prokaryotic DNA ratio make this a highly challenging environment to study with next-generation sequencing (NGS) techniques. Here, we describe the methodological challenges that are typically encountered when performing an accurate analysis of low microbial biomass samples, illustrated by data of our own observational study. In terms of the research question, we compared the microbial composition throughout different parts of the reproductive tract of clinically healthy, mid-lactation Holstein-Friesian cows. Samples were collected from 5 dairy cows immediately after killing. Swabs were taken from the vagina, and from 4 pre-established locations of the uterine endometrium. In addition to the conventional DNA extraction blank controls, sterile swabs rubbed over disinfected disposable gloves and the disinfected surface of the uterus (tunica serosa) before incision were taken as sampling controls. The DNA extraction, DNA quantification, quantitative PCR of the $16 \mathrm{~S}$ rRNA genes, and $16 \mathrm{~S}$ rRNA gene sequencing were performed. In terms of NGS data analysis, we performed prevalence-based filtering of putative contaminant operational taxonomic units (OTU) using the decontam $\mathrm{R}$ package. Although the bacterial composition differed between the vagina and uterus,
\end{abstract}

Received August 31, 2020.

Accepted January 11, 2021.

*Corresponding author: geert.opsomer@ugent.be no differences in bacterial community structure ( $\alpha$ and $\beta$ diversity) were found among the different locations in the uterus. At phylum level, uterine samples had a greater relative abundance of Proteobacteria, and a lesser relative abundance of Firmicutes than vaginal samples. The number of shared OTU between vagina and uterus was limited, suggesting the existence of bacterial transmission routes other than the transcervical one to the uterus. The mid-lactation bovine genital tract is a low microbial biomass environment, which makes it difficult to distinguish between its constitutive versus contaminant microbiome. The integration of key controls is therefore strictly necessary to decrease the effect of accidentally introduced contaminant sequences and improve the reliability of results in samples with low microbial biomass.

Key words: bovine, uterine microbiome, vaginal microbiome, low biomass

\section{INTRODUCTION}

It is challenging to define a consensus of healthy uterine microbiota (Baker et al., 2018). The microbiome of the reproductive tract has been investigated extensively in both humans and animals, and researchers all over the world have been studying the effect of these microbiota on embryo development (Franasiak et al., 2016; Verstraelen et al., 2016; Schoenmakers et al., 2019). In dairy cows, the majority of uterine microbiome studies evaluated associations between bacteria and uterine disease during the immediate postpartum period (Sheldon et al., 2009; Santos and Bicalho, 2012; Jeon et al., 2015). In contrast, microbiome research on the clinically healthy, late-postpartum bovine uterus is scarce (Knudsen et al., 2016; Clemmons et al., 2017; Ault et al., 2019b). Assessing the uterine microbiome has some limitations, regarding its difficult attainability for in vivo sampling. In vivo sampling often 
requires passing the vagina and cervix before reaching the uterine lumen. This transcervical approach implies a serious risk for contamination of the uterine sample with bacteria present in the vagina and cervix. Even by using double-guarded devices, the risk of contamination can be limited, but not eliminated (Täte, 2011; Spilker et al., 2017). Alternatively, ex vivo sampling of uteri retrieved from the slaughterhouse has been done, but slaughtered cows hang upside down, altering the physiologic position of the reproductive tract (Moore et al., 2017). This may have influenced the microbial composition along the reproductive tract, because vaginal fluids, containing (vaginal) bacteria and possibly fecal contaminants, may transverse the cervical canal (Buntain and Nakamura, 1977).

Studies comparing the bacterial composition along the bovine female reproductive tract in mid-lactation generally found a larger number of bacterial operational taxonomic units (OTU) in the vagina than in the uterus (Clemmons et al., 2017; Ault et al., 2019b). Nevertheless, to the best of our knowledge, no studies have been performed to compare the bacterial composition among different locations within the uterus. The distribution of (subclinical) inflammation is however unequal throughout the endometrium of dairy cows (Bogado Pascottini et al., 2016; Pothmann et al., 2019). Therefore, we hypothesized that also the microbiota is unequally distributed along different uterine locations.

Because next-generation sequencing (NGS) techniques have become more affordable, the ability to explore and identify complex bacterial compositions has improved considerably. Notwithstanding the substantial progress made by NGS techniques, proper interpretation of microbiome profiles derived from low microbial biomass environments remains challenging (Glassing et al., 2016; Perez-Muñoz et al., 2017; O'Callaghan et al., 2020). A major limitation when using NGS techniques is (cross-)contamination during sampling as well as during DNA extraction. Eisenhofer et al. (2019) reviewed how contaminant DNA can be introduced in microbiome studies and described key measures to overcome bias originating from this contamination. They developed the RIDE[AU2: Is RIDE an abbreviation for something? If so, please define.] checklist, including a set of minimal experimental criteria to improve low microbial biomass studies. Sampling controls and DNA extraction blank controls, as well as performing subtractive filtering during data analysis to remove putative contaminants from the original data set, are among the RIDE checklist criteria.

The initial objective of the present study was to describe the microbial composition in different parts of the clinically healthy bovine reproductive tract, using $16 \mathrm{~S}$ rRNA gene sequencing analysis. Because we encountered major challenges associated with the interpretation of these low microbial biomass data, we decided to deeply elaborate on the materials and methods. Therefore, besides our original objective, we additionally aimed to bring some concerns regarding low microbial biomass PCR and NGS techniques to the attention of future microbiome researchers and provide a detailed overview of the hurdles to be taken to perform an accurate analysis of low microbial biomass samples in dairy research. Well-considered key measures to minimize the influence of contaminant DNA in our low microbial biomass study were integrated as described in the RIDE checklist (Eisenhofer et al., 2019).

\section{MATERIALS AND METHODS}

\section{Experimental Design and Sample Collection}

Ten Holstein-Friesian cows, culled between 48 and $464 \mathrm{~d}$ postpartum, were enrolled in this observational study. Animals were housed at the Faculty of Veterinary Medicine of Ghent University (Ghent, Belgium) for 1 to $8 \mathrm{~d}$ before they were killed. Cows were examined by a certified veterinarian and were clinically healthy, but no other previous medical nor reproductive records were available. Cows were subjected to laparotomy as practical education for undergraduate veterinary students. This procedure was approved by the Ethical Committee of the Faculty of Veterinary Medicine (2017-89, Ghent University, Belgium). Following laparotomy, cows were killed by intravenous injection of pentobarbital sodium (Release $300 \mathrm{mg} / \mathrm{mL}$, WDT).

Then vaginal samples were collected using sterile swabs (Biolab Inc.). In short, the perineal area of the cow was thoroughly washed with iodide soap and water, dried with paper towel, and disinfected with ethanol (70\%). The swab was introduced in the vagina, advanced carefully up to $20 \mathrm{~cm}$ deep, rolled 3 times (clockwise), and withdrawn. The cotton tip of the swab was immediately detached and placed into a sterile, DNase- and RNase-free microtube (ClearLine, Biosigma) and stored at $-80^{\circ} \mathrm{C}$ within 30 min.

A left abdominal flank incision was made to retrieve the reproductive tract. Intra-abdominally, the vagina was ligated caudally from the cervix, using a tie wrap, and ovariohysterectomy was performed. The entire reproductive tract was exteriorized and immediately transported to the laboratory. Before dissecting the reproductive tract, it was gently rubbed and rinsed with ethanol (70\%). Then, 4 small incisions [tip of the right (RT), base of the right (RB), tip of the left (LT) and base of the left (LB) uterine horn; Supplemental Figure S1[AU3: Per 2021 instructions for authors, supplemental tables and figures should be hosted by the 
authors in a third-party repository of their choosing (e.g., FigShare, Mendeley Data, Dryad) and linked here. Please upload supplemental files to a repository and provide the URL here.]] were made along the major curvature of the uterus, using a sterile singleuse scalpel blade (Swann-Morton) heated red hot by flame. Sterile swabs (Biolab Inc.) were inserted through the incisions and were rolled 3 times (clockwise) against the endometrium. The cotton tip of the swab was then placed into a sterile DNase- and RNase-free microtube (ClearLine, Biosigma), snap-frozen in liquid nitrogen, and stored at $-80^{\circ} \mathrm{C}$.

After sampling, uteri were cut open and macroscopic examination of the reproductive tracts was performed. Five cows were excluded for further analysis based on the following criteria: less than $60 \mathrm{~d}$ postpartum $(\mathrm{n}=$ $2)$, macroscopic abnormalities $(\mathrm{n}=2)$, and retrieval of an incomplete set of samples $(\mathrm{n}=1)$. The remaining cows were on average $4 \mathrm{yr}$ old (range 3.5-5 yr) and 212 d postpartum (range 89-327 d). Three of them had a corpus luteum $(\mathbf{C L})$ on the right ovary, one cow had a CL on the left ovary, and one cow had no CL.

Three extra sampling controls were included. These sampling controls consisted of sterile swabs (Biolab Inc., Budapest, Hungary) rubbed over disinfected (with ethanol $70 \%$ ) disposable gloves $(n=1)$ and the disinfected (with ethanol 70\%) surface of the uterus (tunica serosa) before incision $(\mathrm{n}=2)$. All sampling controls were processed in the same way as the biological samples.

\section{DNA Extraction}

Samples were processed at the Center for Microbial Ecology and Technology, Ghent University, for DNA extraction, using the ZymoBIOMICS DNA Microprep Kit (Zymo Research). Briefly, swabs were transferred to a ZR BashingBead Lysis Tube containing 0.1- and $0.5-\mathrm{mm}$ glass beads and $750 \mu \mathrm{L}$ of ZymoBIOMICS Lysis Solution. Three DNA extraction blank controls were simultaneously included. These DNA extraction blank controls consisted of ZR BashingBead Lysis Tubes with $0.1-$ and $0.5-\mathrm{mm}$ glass beads and $750 \mu \mathrm{L}$ ZymoBIOMICS Lysis Solution, with no swab. These controls allowed the monitoring of contaminant DNA in extraction kits, reagents, and the laboratory environment during DNA extraction and further analyses (Eisenhofer et al., 2019). Bead beating was performed for all samples in a PowerLyzer 24 Bench Top BeadBased Homogenizer (MO BIO Laboratories, Inc.) for $5 \mathrm{~min}$ at 2,000 rpm. Further steps were carried out according to the manufacturer's instructions. The DNA extract quality was verified by gel electrophoresis using
$1.5 \%$ (wt/vol) agarose gel. The position of the bands and the band width were assessed, but no other conclusions were drawn from this. The concentration of the extracted DNA was evaluated by a fluorescence-based assay using the QuantiFluor dsDNA kit (Promega) and GloMax-Multi+ system (Promega). The fluorescent DNA-binding dye enabled a sensitive quantification of small amounts of dsDNA.

\section{S rRNA Gene Quantitative Real-Time PCR}

The quantitative PCR (qPCR) assays were performed using a StepOnePlus real-time PCR system, targeting the V3 region of the 16S rRNA gene (Applied Biosystems). Reactions were performed in a volume of $20 \mu \mathrm{L}$ consisting of $10 \mu \mathrm{L}$ of $2 \times$ iTaq universal SYBR Green supermix (Bio-Rad Laboratories), 2.0 $\mu \mathrm{L}$ of DNA template, $0.8 \mu \mathrm{L}(10 \mu \mathrm{M}$ stock $)$ of each $338 \mathrm{~F}$ (5'-ACTCCTACGGGAGGCAGCAG-3') and 518R (5'-ATTACCGCGGCTGCTGG-3') primers (Bakke et al., 2011; Ghyselinck et al., 2013), and $6.4 \mu \mathrm{L}$ of nuclease-free water. Amplification was as follows: initial denaturation for $2 \mathrm{~min}$ at $95^{\circ} \mathrm{C}$, followed by 40 cycles of $15 \mathrm{~s}$ denaturation at $95^{\circ} \mathrm{C}$, and combined anneal and extension for $1 \mathrm{~min}$ at $60^{\circ} \mathrm{C}$. Quantification was performed using a standard curve based on known concentrations of DNA standard dilutions from $10^{7}$ copies/ $\mu \mathrm{L}$ down to 100 copies $/ \mu \mathrm{L}$. All qPCR analyses were conducted in duplicates. For 6 samples (RB3, LT1, LT4, LB5, VAG3, and VAG4) qPCR analysis was unsuccessful, but could not be reperformed due to insufficient volume of DNA extract.

\section{Microbial Community Analyses}

The microbial community was analyzed using Illumina MiSeq 16S rRNA gene amplicon sequencing (Illumina). All samples were sent out to BaseClear BV (Leiden, the Netherlands) for library preparation and sequencing on an Illumina MiSeq platform. In short, barcoded amplicons from the V3 to V4 regions of $16 \mathrm{~S}$ rRNA genes were generated using a 2-step PCR. Ten to $25 \mathrm{ng}$ of genomic (g)DNA was used as template for the first PCR with a total volume of $50 \mu \mathrm{L}$ using the $341 \mathrm{~F}$ (5'-CCTACGGGNGGCWGCAG-3') and the 785R (5'-GACTACHVGGGTATCTAATCC-3') primers appended with Illumina adaptor sequences. Purified PCR products were used for a second PCR in combination with sample-specific barcoded primers (Nextera XT index kit, Illumina). Subsequently, PCR products were purified, checked on a Fragment analyzer (Advanced Analytical Technologies, Inc.), and quantified. This was followed by multiplexing, clustering, and sequencing on 
an Illumina MiSeq with the paired-end $(2 \times)$ 300-bp protocol and indexing. The sequencing run was analyzed with the Illumina CASAVA pipeline (v1.8.3) with demultiplexing based on sample-specific barcodes.

The MOTHUR software package (v.1.42.3[AU4: Add a reference or provide URL for software and database below.]) was used to process the raw sequence reads generated by BaseClear BV (Schloss et al., 2009; Kozich et al., 2013). After assembling paired-end reads, contigs with a length between 400 and 430 bases were aligned to the MOTHUR formatted SILVA database (v132). A quality check was performed (maximum number of homopolymers is 12 bases, sequences are preclustered allowing up to 4 differences) and VSEARCH was applied to remove chimeras (Rognes et al., 2016). Subsequently, sequences were classified to the SILVA $16 \mathrm{~S}$ rRNA reference database (v132). Sequences derived from an unknown domain, Eukaryota, Archaea, chloroplasts, or mitochondria were removed. The OTU were generated de novo by clustering sequences found to be more than $97 \%$ similar to the V3 and V4 regions of their 16S rRNA gene after applying hierarchical clustering (Schloss et al., 2009; Schloss and Westcott, 2011).

Because there was a significant dropout of sequences along the pipeline, especially in the uterine samples, we also performed hierarchical clustering and generation of OTU without prior removal of chloroplast and mitochondrial sequences. This data set was only used to assess the abundance of chloroplast and mitochondria in the samples, and not for further analysis. The sequence data have been submitted to the NCBI (National Center for Biotechnology Information) database under accession number PRJNA656386.

\section{Statistical Analyses}

The OTU table with taxonomy assignments was processed using the $\mathrm{R}$ language for statistical programming (v3.6.0; https://www.r-project.org). First, the sampling controls $(\mathrm{n}=3)$ were excluded from the original NGS data set. Second, identifying and controlling for contaminant bacterial DNA is critical in understanding microbial communities from low microbial biomass samples. Accordingly, prevalence-based filtering of putative contaminant OTU was performed using the decontam R package (v1.6.0, Davis et al., 2018). Probable contaminant OTU were depicted in the NGS data set using the isContaminant function, comparing their prevalence in biological samples and in DNA extraction blank controls. Probable noncontaminant OTU were depicted using the isNotContaminant function. For both computations, the default settings were maintained $($ method $=$ prevalence, threshold $=$
0.5 , normalize $=$ TRUE, detailed $=$ TRUE). A decontaminated data set was composed, containing solely all probable noncontaminant OTU, selected using the isNotContaminant function.

Descriptive statistics were calculated for all samples, both on the original NGS data set as well as after decontamination. The normality of the distributions was verified using histograms and Shapiro-Wilks tests. Subsequently, for the biological samples, the data were grouped by anatomical location along the reproductive tract, and for the control samples, grouped by type (sampling control vs. DNA extraction blank control). Differences in number of OTU, number of $16 \mathrm{~S}$ rRNA gene sequence reads, dsDNA concentration, and $16 \mathrm{~S}$ rRNA gene copy number between locations, and between biological samples and controls were analyzed using the Kruskal-Wallis rank sum test and post hoc Dunn's test for all pairs of comparisons between groups (multilevel), or using the Wilcoxon rank sum tests (2-level). A nonparametric Spearman test was performed to calculate the correlation between the dsDNA concentration and the $16 \mathrm{~S}$ rRNA gene copy number. Analyses and visualization were done using the $\mathrm{R}$ packages dunn.test (v1.3.5, Dinno, 2017), phyloseq (v1.30.0, McMurdie and Holmes, 2013), ggplot2 (v3.3.0, Wickham, 2010), and microbiome (v1.8.0, Lahti et al., 2017). Any other statistics were performed on the decontaminated data set only. A heatmap visualization was generated using the plot_heatmap function of the phyloseq package. The OTU-level $\alpha$-diversity indices (inverse Simpson and Shannon) were calculated for the biological samples, using the estimate_richness function of the phyloseq package. Venn diagrams showing the number of OTU in the bovine uterus and vagina were created ( $\mathrm{R}$ package limma, v3.42.2, Ritchie et al., 2015). The simper function ( $\mathrm{R}$ package vegan, v2.5.6, Oksanen et al., 2019) was used to set the similarity percentages and to extract the most discriminating bacteria (at family and phylum level) to compare their relative abundance by uterine location (RT, RB, LT, LB) and between uterus and vagina using Kruskal-Wallis rank sum tests. Moreover, linear discriminant analysis effect size (Segata et al., 2011) was implemented to indicate the most discriminating bacteria (at the family and phylum level) between uterine locations, and between uterus and vagina ( $\alpha$ of 0.05 and effect size threshold of 3.5). Visualization of the sample profiles according to Bray-Curtis dissimilarities was done using principalcoordinate analysis (PCoA) plots. A permutest ( $\mathrm{R}$ package vegan) was performed to test for multivariate homogeneity of the group dispersions and PERMANOVA tests (adonis function, $R$ package vegan) were then performed. Differences were considered significant at $P$ $<0.05$. 
The prevalence-based filtering of putative noncontaminant OTU was also performed based on the out[AU5: Should this be OTU?] in each sampling control. To do so, all biological samples and the sampling controls were decontaminated based on the prevalence of the OTU in the samples and in the DNA extraction blank controls, as described above. Subsequently, the putative noncontaminant OTU of the uterine samples were prevalence-based filtered based on the prevalence of the putative noncontaminant OTU of the sampling controls. A bar chart was drawn for this new, double decontaminated uterine data set (Supplemental Figure S3[AU6: Provide URL for supplemental material.]). No further analyses were performed with this data set. To allow transparency in the data exploration and statistical analysis, the code is publicly available at https://github.com/Bovi-analytics/Lietaer_bovine _reproductive_microbiome.

\section{RESULTS}

\section{Quantification of dsDNA and Bacterial DNA}

The QuantiFluor measurements of dsDNA in the DNA extraction blank controls did not exceed the background technical control of the method (as close to $0 \mathrm{ng} / \mu \mathrm{L}$ ). Also, the $16 \mathrm{~S}$ rRNA gene copy numbers of the DNA extraction blank controls were close to the background technical control of the method (median $3.2 \log _{10} 16 \mathrm{~S}$ rRNA gene copy numbers/ $\mu \mathrm{L}$ of DNA extract). The sampling controls held small amounts of dsDNA (median $2 \mathrm{ng} / \mu \mathrm{L}$ of DNA extract, range 0 to $2 \mathrm{ng} / \mu \mathrm{L}$ of DNA extract), as well as low numbers of $16 \mathrm{~S}$ rRNA gene copies (median $5.5 \log _{10} 16 \mathrm{~S}$ rRNA gene copy numbers $/ \mu \mathrm{L}$ of DNA extract, range 3.4 to $6.2 \log _{10} 16 \mathrm{~S}$ rRNA gene copy numbers $/ \mu \mathrm{L}$ of DNA extract). The amount of dsDNA and the $16 \mathrm{~S}$ rRNA gene copy numbers were significantly[AU7: Please add P-value anywhere "significant" refers to statistical significance, and consider using another word when "significant" refers to importance.] larger for the uterine and vaginal samples (median $141.9 \mathrm{ng}$ of dsDNA/ $\mu \mathrm{L}$ of DNA extract, range 42.8 to $230.1 \mathrm{ng}$ of $\mathrm{dsDNA} / \mu \mathrm{L}$ of DNA extract; and median $6.9 \log _{10}$ $16 \mathrm{~S}$ rRNA gene copy numbers/ $\mu \mathrm{L}$ of DNA extract, range 6.7 to $7.0 \log _{10} 16 \mathrm{~S}$ rRNA gene copy numbers/ $\mu \mathrm{L}$ of DNA extract) than for the control samples $(P$ $<0.001$ ). Yet, no differences in amount of dsDNA and 16S rRNA gene copy numbers were detected among uterine locations nor between uterus and vagina $(P>$ 0.05; Supplemental Table S1[AU8: Add URL for supplemental material.]). No significant correlation ( $\mathrm{r}=$ 0.24) was found between the QuantiFluor measurement and $\mathrm{qPCR}$ result of the biological samples.

\section{Microbial Community Analyses: Descriptive Statistics}

The 16S rRNA gene amplicon sequencing of 25 biological samples (uterine lumen $=20$, vagina $=5$ ), 3 sampling controls, and 3 DNA extraction blank controls generated a total of 1,037,935 contigs. After removing low-quality sequences, 591,202 clean bacterial sequences were used for further analyses, with a minimum and maximum read count of 150 and 117,681 per sample, respectively. All effective reads were clustered into OTU (at 97\% sequence identity). Before decontamination, the OTU table (including all biological samples, sampling controls, and DNA extraction blank controls) contained 4,787 OTU, $64.7 \%$ of which were singletons. The summary statistics of the total read counts and number of OTU per sample type is shown in Table 1. The relative distribution of the most abundant phyla and OTU over all samples in the nondecontaminated data set (biological samples, sampling controls, and DNA extraction blank controls) is shown in Figure 1.

\section{Microbial Community Analyses: Decontamination}

Facing the issue of shared OTU between the biological and control samples, prevalence-based filtering of putative contaminant OTU was performed; 112 OTU were indicated to represent putative bacterial contaminants in our original NGS data set. Using the isNotContaminant function, 563 bacterial OTU were acknowledged as being no contaminants. Figure 2 shows how individual OTU were classified (contaminant or no contaminant) according to both computations, based on their prevalence in the biological samples $(\mathrm{n}=25)$ versus in the DNA extraction blank controls $(\mathrm{n}=3)$. The summary statistics of the total read count of noncontaminant reads and number of noncontaminant OTU per sample type is shown in Table 2.

\section{Microbial Community Analyses: Taxonomic Identification}

The relative abundance of the most abundant OTU over all biological samples in the decontaminated data set is shown in Figure 3 and 4 (phylum level and family level). The 5 most abundant noncontaminant families in the biological samples were Pseudomonadaceae, Burkholderiaceae, Enterobacteriaceae, Pasteurellaceae, and Ruminococcaceae. The vaginal samples and sample LB5 (from the base of the left uterine horn of cow 5) showed a distinct pattern, Ruminococcaceae, Pasteurellaceae, Enterobacteriaceae, Mycoplasmataceae, and Rikenellaceae as the 5 most abundant families (Figure 3 and Supplemental Figure S3[AU9: Add URL for 


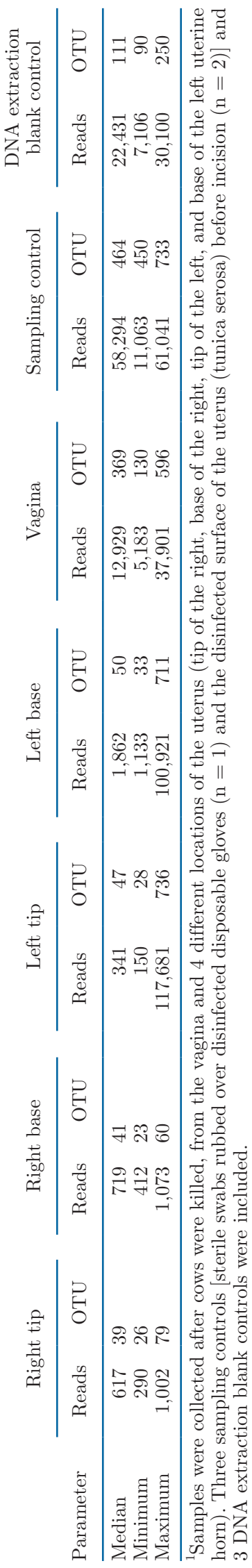

supplemental material.]). At the genus level, vaginal sample VAG2 displayed high dominance by Escherichia-Shigella (around 70\%) and VAG1 and VAG5 showed a predominantly combined presence of Ureaplasma and Histophilus. Figure 5 shows the number of OTU that remained after decontamination, uniquely identified at the different locations of the reproductive tract (RT, RB, LT, LB, and vagina). In the same figure, also the number of shared OTU was given for the locations in anatomical proximity.

\section{Microbial Community Analyses: $\alpha$ and $\beta$ Diversities}

Alpha diversity indices (inverse Simpson and Shannon) and $\beta$ diversity (Bray-Curtis dissimilarity) were not different at the OTU level (in the decontaminated data set) between the 4 uterine locations (RT, RB, LT, and LB). Alpha diversity index Shannon was different between uterine and vaginal samples (Figure $6 \mathrm{~A})$. Beta diversity showed differences in the bacterial community structure, with vaginal samples clustered tightly, whereas uterine samples were less clustered, but distinctly separated from the vaginal samples (Figure $6 \mathrm{~B})$. At the phylum level (in the decontaminated data set), uterine samples had a greater relative abundance of Proteobacteria, and a lesser relative abundance of Firmicutes than vaginal samples (Figure 7). At the family level, uterine samples had a greater relative abundance of Pseudomonadaceae and Burkholderiaceae, but a lower relative abundance of Pasteurellaceae, $R u$ minococcaceae, Mycoplasmataceae, Rikenellaceae, Corynebacteriaceae and Lachnospiraceae than the vaginal samples (Figure 8 and 9B).

\section{DISCUSSION}

The healthy bovine uterus has traditionally been considered as a sterile entity. However, NGS techniques and fluorescence in situ hybridization, have demystified this assumption as recent studies have identified bacterial DNA and RNA in healthy mid-lactation as well as pregnant bovine uteri (Knudsen et al., 2016; Karstrup et al., 2017; Moore et al., 2017; Ault et al., 2019a, b). The high sensitivity of NGS techniques is a doubleedged sword, because contaminant sequences can be detected as easily as biologically relevant microbial sequences. Some researchers still interpret the identification of microbiota in the healthy uterus and placenta as intrauterine infections or contamination (Lauder et al., 2016; Eisenhofer et al., 2018[AU10: Should this be "Eisenhofer et al., 2019"? If not, add to refs.]; de Goffau et al., 2019). Therefore, researchers have been promoting heightened awareness for erroneous NGS 

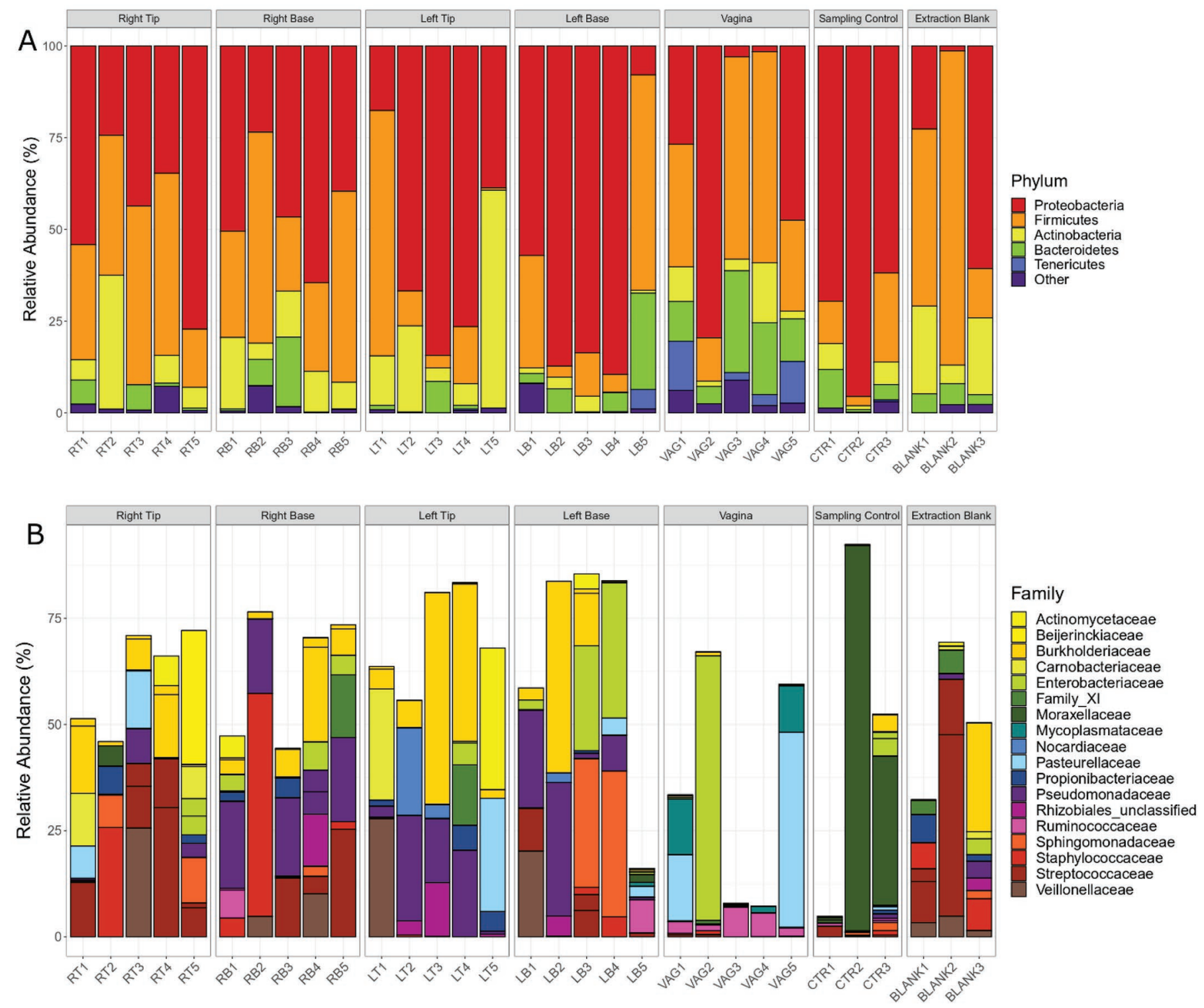

Figure 1. Relative abundance of bacteria detected in the reproductive tract of mid-lactation dairy cows ( $\mathrm{n}=5$; nondecontaminated data set). Samples were collected after the cows were killed, from the vagina and 4 different locations of the uterus [tip of the right (RT), base of the right (RB), tip of the left (LT), and base of the left (LB) uterine horn]. Three sampling controls [sterile swabs rubbed over disinfected disposable gloves $(\mathrm{n}=1)$ and the disinfected surface of the uterus (tunica serosa) before incision $(\mathrm{n}=2)]$ and 3 DNA extraction blank controls were included. (A) Bar chart representing the relative abundance of the 5 most abundant bacterial phyla. (B) Bar chart representing the relative abundance of the 25 most abundant operational taxonomic units.

results (Goodrich et al., 2014; Eisenhofer et al., 2019; Karstens et al., 2019).

In the current study, bacterial DNA was identified along the different locations of the mid-lactation female bovine reproductive tract, using $16 \mathrm{~S}$ rRNA gene sequencing analysis and in silico filtering for putative contaminant sequences. We included several integrated key controls, according to the RIDE checklist (Eisenhofer et al., 2019), to decrease the effect of accidentally introduced contaminant sequences, thus improving the reliability of our study. First, the examination of reproductive tracts retrieved from cows killed in a clinical setting was preferred over the use of slaughterhouse material, or in vivo sampling using the transcervical approach. Sampling controls, as well as DNA extraction blank controls, were included, and the bacterial load in the samples and controls was assessed. To this end, in a naïve approach, we quantified the extracted dsDNA using QuantiFluor measurement. Because our biological samples contained large amounts of competitive bo- 

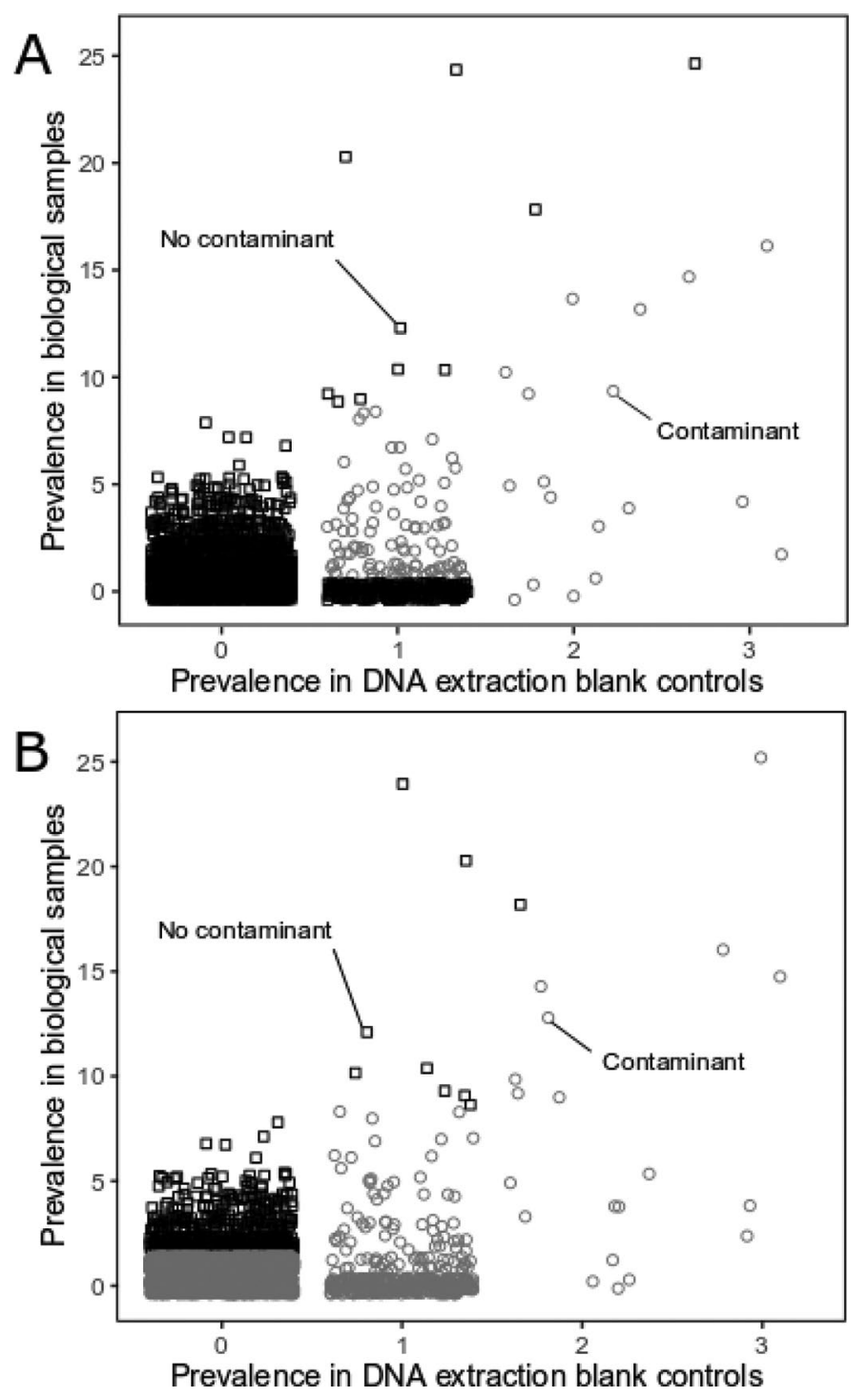

Figure 2. Jitter plots showing the prevalence of every operational taxonomic unit (OTU) detected in the reproductive tract of mid-lactation dairy cows $(\mathrm{n}=5)$ versus their prevalence in the DNA extraction blank controls $(\mathrm{n}=3)$. The biological samples were collected after the cows were killed, from the vagina and 4 different locations of the uterus (tip of the right, base of the right, tip of the left, and base of the left uterine horn). (A) According to the isContaminant function of the decontam R package (v1.6.0, Davis et al., 2018), 112 OTU were statistically denoted to be contaminant. (B) According to the isNotContaminant function of the decontam $\mathrm{R}$ package, 563 OTU were statistically denoted to be noncontaminant OTU. For low microbial biomass sample types, the isNotContaminant function is recommended. Gray circles show contaminant OTU and black squares show no contaminant OTU.

vine (host) DNA, the quantification of total dsDNA resulted in an overestimation of the amount of bacterial DNA. Consequently, qPCR was performed, specifically targeting the V3 hypervariable region of the bacterial 16S rRNA gene. We found no significant correlation between the QuantiFluor measurement and $\mathrm{qPCR}$ result of the biological samples. The bacterial DNA quantity was significantly higher in our biological samples than in the technical controls, but no differences between the locations along the reproductive tract were noted. This last observation was contrasting human reproductive tract studies, finding higher bacterial loads in vaginal than in uterine samples (Lauder et al., 2016; Chen et al., 2017). However, very limited numbers of papers discuss quantitative microbiome measures in cattle. Our qPCR results are debatable, possibly more nonbacterial DNA sequences were erroneously picked up in the uterine than in the vaginal samples. Although the $\mathrm{qPCR}$ primers were not the same as the Illumina primers, we noticed a higher proportion of chloroplast and mitochondrial sequences in the $16 \mathrm{~S}$ rRNA gene sequencing results in the uterine samples (Supplemental Figure S2[AU11: Add URL for supplemental material.]). This gives us an indication that $\mathrm{qPCR}$ and NGS techniques might be less specific in biological samples, with a high eukaryotic/prokaryotic DNA ratio.

Unexpectedly, after $16 \mathrm{~S}$ rRNA gene amplicon sequencing, the total read counts of our technical controls were higher than the total read counts of our biological samples. However, read counts are not adequate estimates for the total bacterial load (Props et al., 2017; O'Callaghan et al., 2020). For example, raising the number of PCR cycles can dramatically influence the number of identified sequences. Furthermore, the NGS efficiency may largely vary among samples, depending on their background noise, including host DNA, debris, calcium ions, and organic matter (Pollock et al., 2018). In DNA extraction blank controls, containing no competitive host DNA, the NGS reagents can, therefore, interact differently than in biological samples (Glassing et al., 2016). Furthermore, in this experiment, after the 2-step PCR of the library preparation, equimolar amounts of each sample were mixed to enhance the efficiency of the $16 \mathrm{~S}$ rRNA gene sequencing. This implies dilution of samples containing higher bacterial loads to the level of samples with lower bacterial loads (for example the extraction blank controls), causing an artificial variation in the observed number of reads per sample (Vandeputte et al., 2017).

The low read counts and low number of OTU from our biological samples were consistent with the read counts and OTU numbers found in virgin and pregnant bovine uteri as described by Moore et al. (2017), but were lower than those found in mid-lactation dairy cows by Clemmons et al. (2017). Nonetheless, due to different sampling techniques, comparisons among different studies remain difficult.

The sampling controls taken in the present study demonstrated a clear Acinetobacter signature, which was not consistently present in the biological samples. 
Table 2. Summary statistics of the total read count and the number of operational taxonomic units (OTU) detected in the reproductive tract of mid-lactation dairy cows $(\mathrm{n}=5 \text {; decontaminated data set })^{1}$

\begin{tabular}{|c|c|c|c|c|c|c|c|c|c|c|c|c|}
\hline \multirow[b]{2}{*}{ Parameter } & \multicolumn{2}{|c|}{ Right tip } & \multicolumn{2}{|c|}{ Right base } & \multicolumn{2}{|c|}{ Left tip } & \multicolumn{2}{|c|}{ Left base } & \multicolumn{2}{|c|}{ Vagina } & \multicolumn{2}{|c|}{$\begin{array}{l}\text { DNA extraction } \\
\text { blank control }\end{array}$} \\
\hline & Reads & OTU & Reads & OTU & Reads & OTU & Reads & OTU & Reads & OTU & Reads & OTU \\
\hline Median & 149 & 13 & 308 & 13 & 197 & 18 & 900 & 14 & 9,300 & 177 & 275 & 2 \\
\hline Minimum & 93 & 8 & 106 & 8 & 31 & 9 & 378 & 12 & 3,807 & 45 & 2 & 1 \\
\hline Maximum & 284 & 26 & 482 & 18 & 85,249 & 146 & 89,104 & 167 & 30,066 & 244 & 10,944 & 7 \\
\hline
\end{tabular}

${ }^{1}$ Samples were collected after cows were killed, from the vagina and 4 different locations of the uterus (tip of the right, base of the right, tip of the left, and base of the left uterine horn). Three DNA extraction blank controls were included.
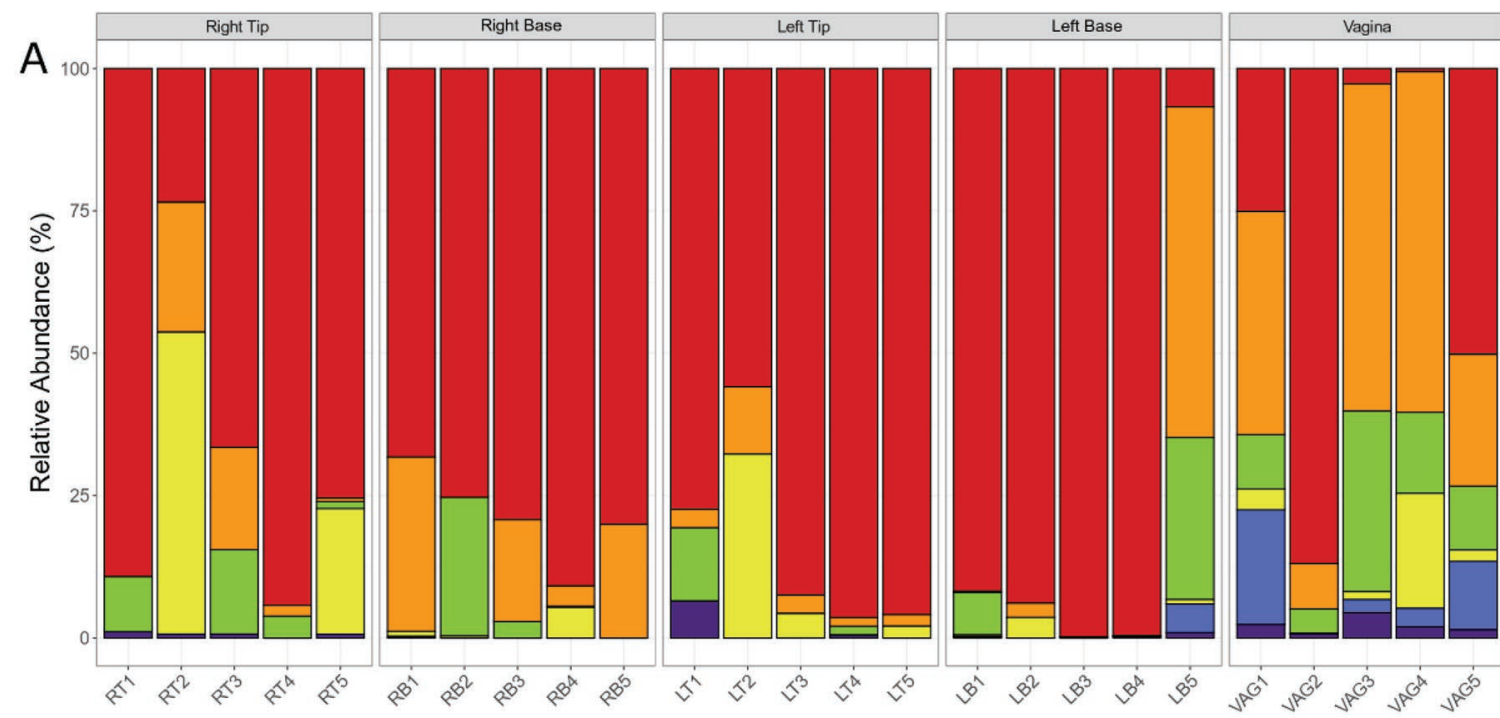

\section{Phylum}

$\square$ Proteobacteria

Firmicutes

Bacteroidetes

Bacteroidetes

Tenericutes

Other

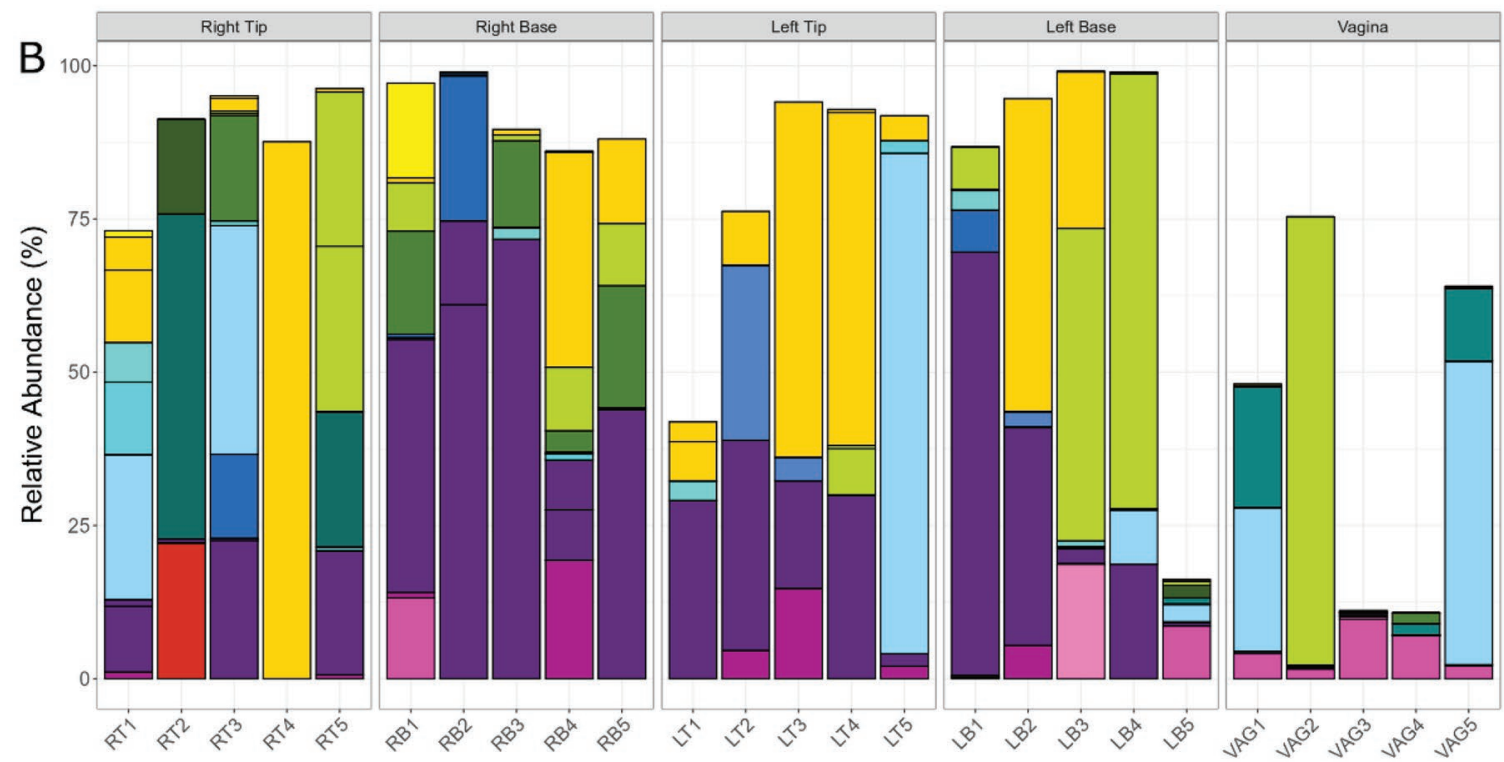

Family

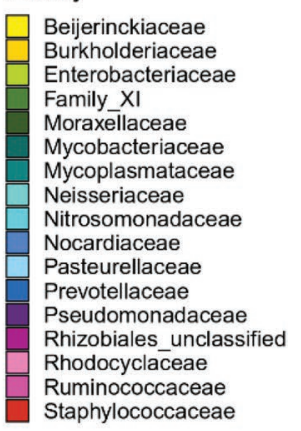

Figure 3. Relative abundance of bacterial taxa detected in the reproductive tract of mid-lactation dairy cows $(\mathrm{n}=5)$. Samples were collected after the cows were killed, from the vagina and 4 different locations of the uterus [tip of the right (RT), base of the right (RB), tip of the left (LT), and base of the left (LB) uterine horn]. Only operational taxonomic units (OTU) remaining after decontamination of the sequencing data set using the isNotContaminant function of the decontam package were included. (A) Bar chart representing the relative abundance of the 5 most abundant bacterial phyla. (B) Bar chart representing the relative abundance of the 25 most abundant OTU. 
Therefore, contamination originating from the sampling procedure itself was rather low. It can be assumed that Acinetobacter is related to the surgery before sampling or the used disinfectant (Doughari et al., 2011). The DNA concentration of the sampling controls ranged between $10^{3} 16 \mathrm{~S}$ rRNA gene copies/ $\mu$ l DNA extract (close to $\mathrm{qPCR}$ background level) for the disinfected glove, and $10^{6}$ copies/ $\mu \mathrm{L}$ DNA extract for the surface of the disinfected uterus. Because ethanol is only killing bacteria, and not completely removing bacterial DNA, it is expected to find bacterial sequences by performing 16S rRNA gene sequencing in control, disinfected samples. Both the Acinetobacter signature and the DNA concentration suggest these sampling controls were not informative for downstream in silico contaminant filtering, and so the sampling controls were excluded. As a limitation of this experiment, we did not take sampling controls during the vaginal swab collection. Environmental contamination should be taken into consideration, and a swab exposed to air should have been a good estimate for that.

Some highly prevalent OTU in the current data set were shared between the biological samples and the DNA extraction blank controls, indicating the large risk for contamination during DNA extraction and gene sequencing. Using the decontam $\mathrm{R}$ package, in silico prevalence-based filtering of putative contaminant OTU was performed. Only those bacterial OTU that are probable noncontaminant OTU were withheld for further analyses. This approach is the best suitable approach for low microbial biomass samples (Davis et al., 2018; Karstens et al., 2019). Nevertheless, there is a risk of excluding bacteria from the OTU table that are truly present in the sample, but for which statistical

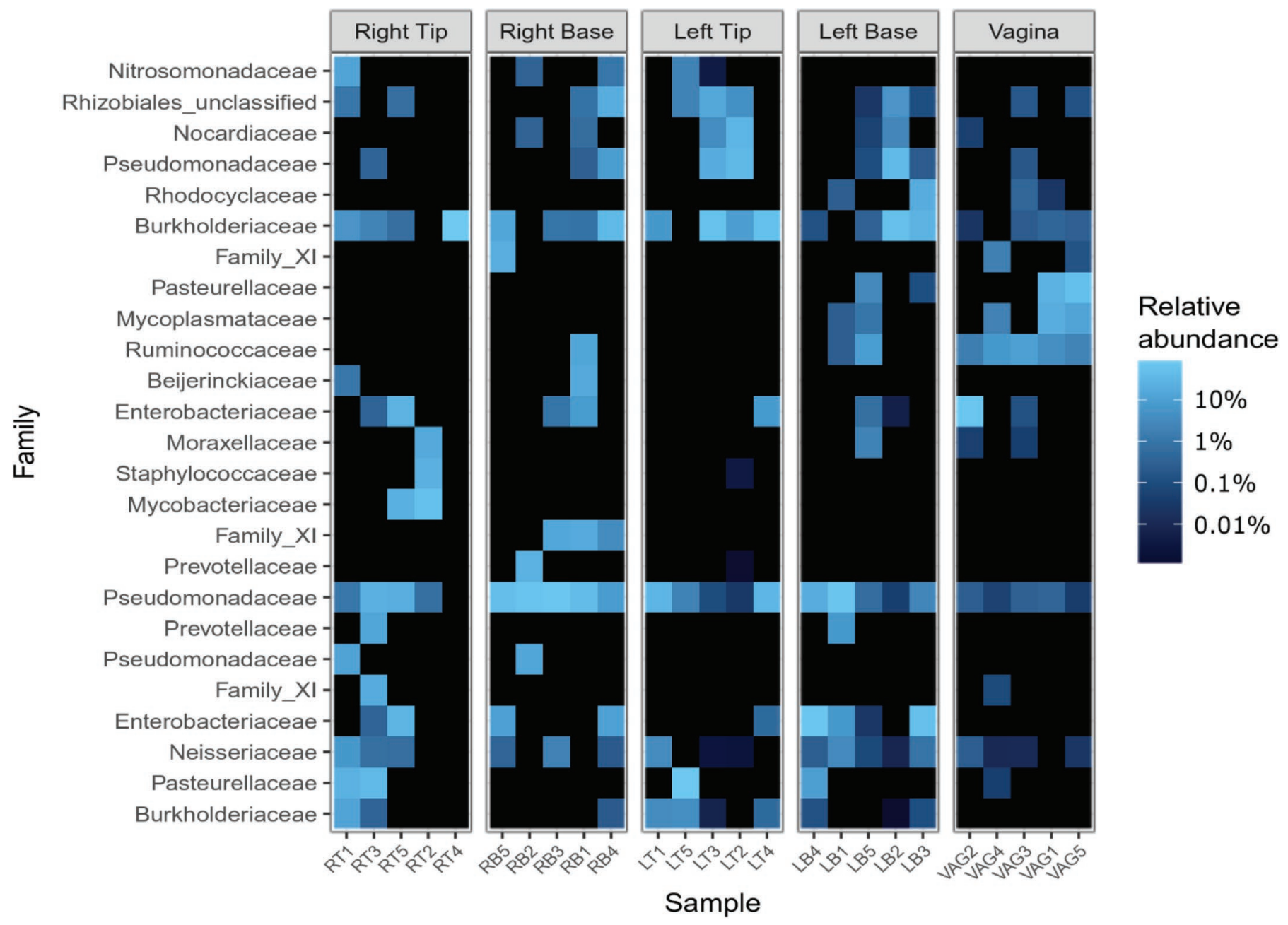

Figure 4. Heatmap showing the relative abundance of the 25 most abundant operational taxonomic units (classified at the family level) detected in the reproductive tract of mid-lactation dairy cows $(n=5)$, grouped by location and clustered based on Bray-Curtis distance (decontaminated data set). Samples were collected after the cows were killed, from the vagina and 4 different locations of the uterus [tip of the right $(\mathrm{RT})$, base of the right (RB), tip of the left (LT), and base of the left (LB) uterine horn]. 


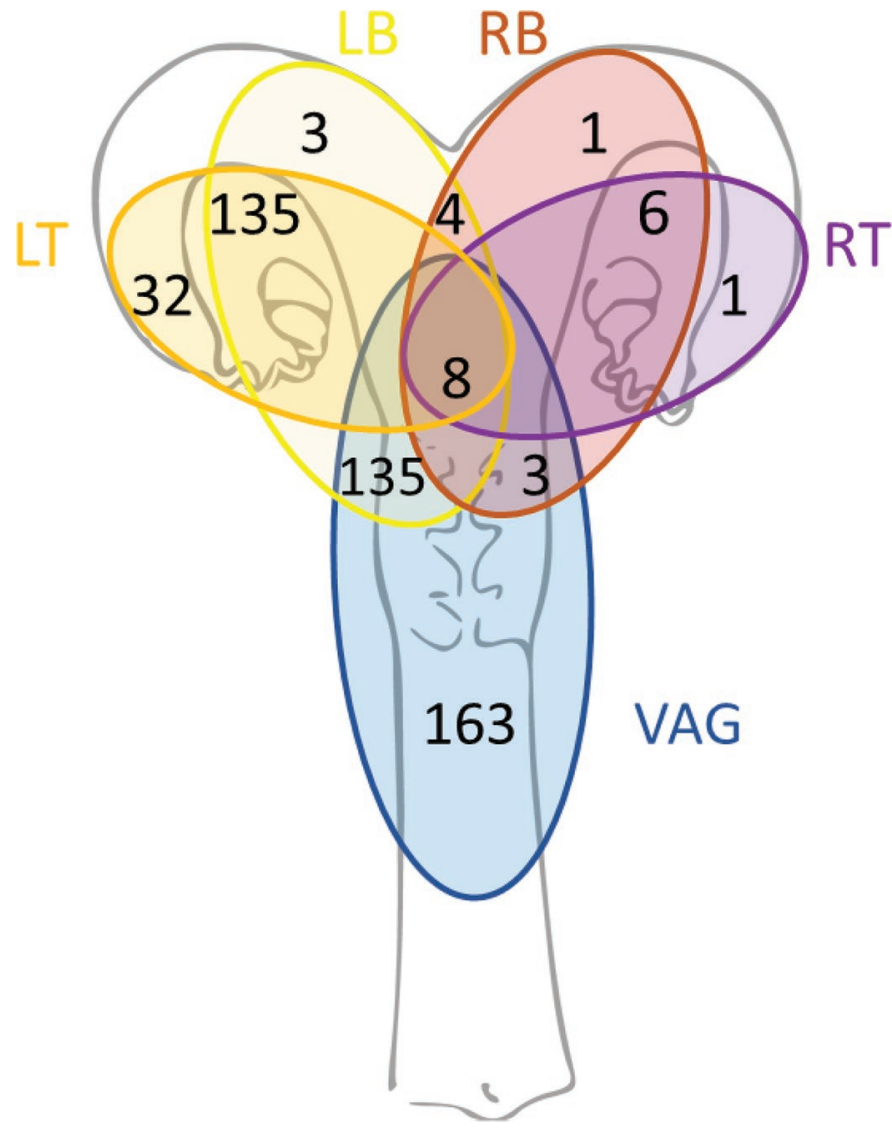

Figure 5. Venn diagram representing the unique and shared operational taxonomic units (OTU) detected in the reproductive tract of mid-lactation dairy cows $(\mathrm{n}=5$; decontaminated data set). Samples were collected after the cows were killed, from the vagina and 4 different locations of the uterus [tip of the right (RT), base of the right (RB), tip of the left (LT), and base of the left (LB) uterine horn]. Shared OTU were only represented for locations along the reproductive tract in anatomical proximity.

evidence is lacking. In contrast, removing all sequences from the OTU table matching the negative controls would induce even larger bias (Goodrich et al., 2014; Pollock et al., 2018; Karstens et al., 2019). Until now, in silico identification and removal of contaminant DNA sequences have not frequently been done in studies performing bovine reproductive tract microbiome analyses. However, in human reproductive tract microbiome research, in silico filtering contaminant sequences is routinely implemented (Seferovic et al., 2019; Theis et al., 2019; O'Callaghan et al., 2020). Interestingly, the decontamination process had a greater effect on the most abundant bacteria in the uterus than in the vagina (Supplemental Figures S3, S4, and S5[AU12: Add URL for supplemental material]). Upon decontamination, a substantial number of bacteria belonging to the 25 most abundant OTU in the nondecontaminated data set from the uterine samples were removed. These
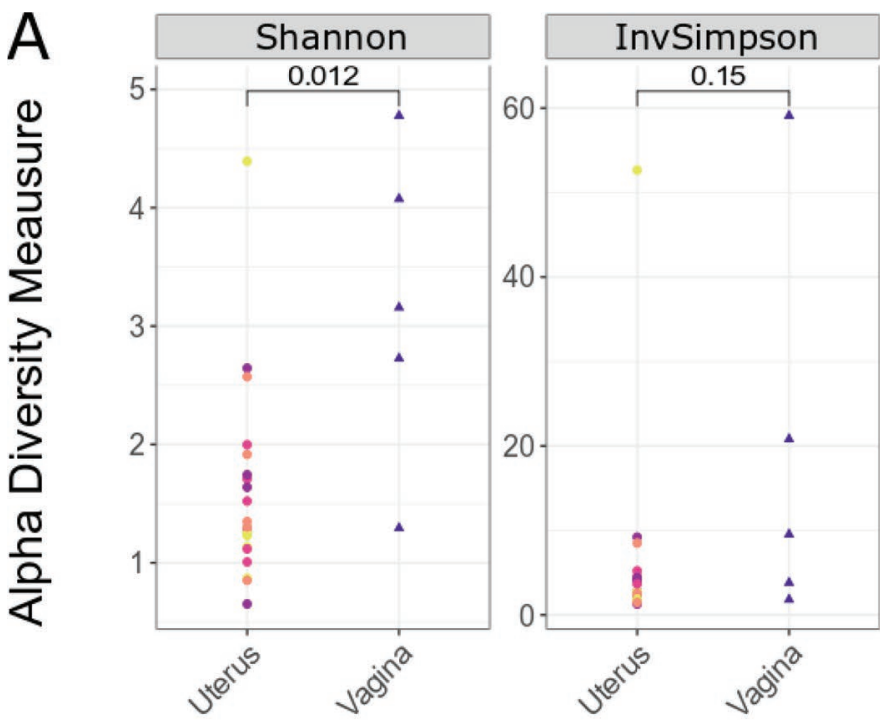

Vagina Right Tip Right Base Left Tip Left Base

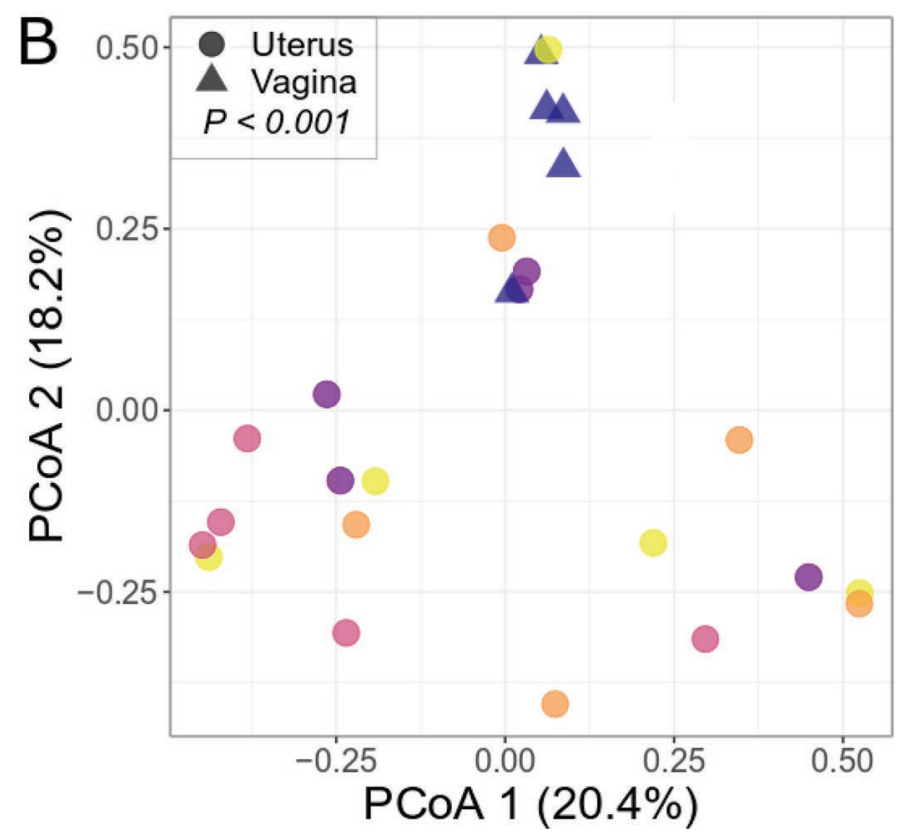

Figure 6. Bacterial community structure of the reproductive tract of mid-lactation dairy cows $(\mathrm{n}=5$; decontaminated data set). Samples were collected after the cows were killed, from the vagina and 4 different locations of the uterus (tip of the right, base of the right, tip of the left, and base of the left uterine horn). (A) Alpha diversity [operational taxonomic unit (OTU) level]. (B) Beta diversity (principal-coordinate analysis , PCoA; Bray-Curtis distances; OTU level). InvSimpson = inverse Simpson.

belonged to bacterial families Actinomycetaceae, Sphingomonadaceae, Streptococcaceae[AU13: Please verify this is correct as edited.], and Veillonellaceae. At the phylum level, barely any other bacteria than Proteo- 

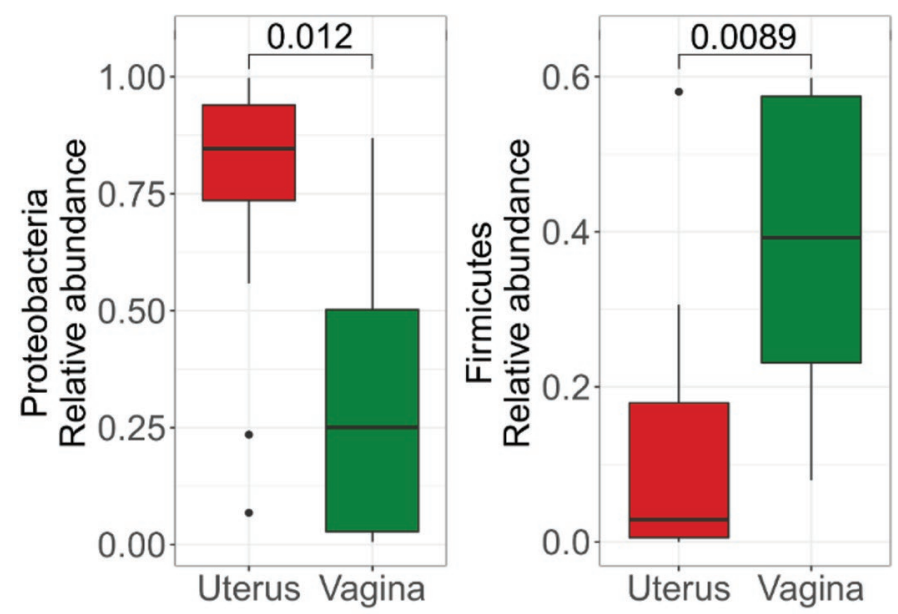

Figure 7. Box plots of the relative abundance of the most discriminating bacterial phyla in mid-lactation dairy cows $(\mathrm{n}=5$, decontaminated data set) in vaginal versus uterine samples. Samples were collected after the cows were killed, from the vagina and 4 different locations of the uterus (tip of the right, base of the right, tip of the left, and base of the left uterine horn). Uterine samples had larger abundance of Proteobacteria and lesser abundance of Firmicutes than vaginal samples[AU19: Please define all elements of box plots: boxes, midline, whiskers, dots.]

bacteria remained after decontamination. In contrast, the bacterial composition of the 25 most abundant OTU in the vaginal samples was more stable. Previous studies with dilution series of mock community samples observed a relatively larger proportion of contaminant bacteria in samples containing lower concentrations of (resident) bacterial DNA (Eisenhofer et al., 2019; Karstens et al., 2019).

In the current study, no significant differences were found in bacterial community structure ( $\alpha$ and $\beta$ diversities) between the different locations (RT, RB, LT, and LB) of the bovine uterus. Nevertheless, the distribution of subclinical inflammation (presence of polymorphonuclear neutrophils) was found to be unequal throughout the endometrium of clinically healthy dairy cows (Bogado Pascottini et al., 2016; Pothmann et al., 2019). Caveats in our study are associated with a relatively low sample size $(\mathrm{n}=5)$, and the low microbial concentration. Therefore, results regarding the distribution of bacteria among different uterine locations should be interpreted with caution. Yet, the bacterial community structure ( $\alpha$ and $\beta$ diversities) of the vagina showed statistically significant differences with the bacterial community structure of the uterus, which is in accordance with previous studies (Ault et al., 2019a). It has been assumed that during parturition the microbiota of the vaginal and uterine compartment are mixed and differentiate again early postpartum (Miranda-CasoLuengo et al., 2019). The closed cervix apparently enables functional compartmentalization in the (bovine) female reproductive tract, in order for the uterine environment (and microbiome) to develop differently than the vaginal environment. The most abundant bacterial families found in the vaginal samples support previous research on the bovine vaginal microbiome (Swartz et al., 2014; Laguardia-Nascimento et al., 2015; Clemmons et al., 2017). Interestingly, the vaginal microbiome coincided with bacteria highly present in the bovine gastrointestinal tract and feces, including Ruminococcaceae, Lachnospiraceae, Bacteroidaceae, Clostridiaceae, Rikenellaceae, and Porphyromonadaceae (Laguardia-Nascimento et al., 2015; Alipour et al., 2018; Klein-Jöbstl et al., 2019). Nevertheless, standard DNA-based NGS techniques are unable to distinguish cell-free DNA from DNA from viable (and also dead) cells, nor among resident bacteria from pathogens or accidentally introduced bacteria ( $\mathrm{Li}$ et al., 2017; O'Callaghan et al., 2020). We did not visualize or assess the viability of bacteria (e.g., FISH or bacterial culturing). Therefore, it remains challenging to associate our findings of specific bacterial sequences with their potential biological relevance (de Goffau et al., 2018[AU14: Should this be "de Goffau et al., 2019"?]; Seferovic et al., 2019; Theis et al., 2019).

One sample (LB5; from the base of the left uterine horn of cow number 5) demonstrated a pattern similar to the vaginal samples. Except for this sample, only a limited number of shared OTU were found between the vaginal and uterine samples. Uterine seeding with bacteria ascending from the vagina, and fecal bacteria contaminating the vagina, has been considered evident (Kunz et al., 1997; Sisti et al., 2016; Jeon et al., 2017). Nonetheless, in accordance with our results, showing only limited agreement between the microbial composition of the vagina and the uterus, other transmission routes should be considered. Accordingly, hematogenous spread of bacteria and bacterial components, from the intestines and other body compartments up to the reproductive tract, is plausible (Laguardia-Nascimento et al., 2015; Jeon et al., 2017). Consequently, it cannot be ruled out that bacteria may have been introduced into the systemic circulation during laparotomy or euthanasia, translocated to the uterus and erroneously identified as resident uterine microbiota. Because the uterine lumen was approached transmural instead of transvaginal, the risk of cross-contamination of the uterine samples with vaginal bacteria was minimized in the current study, making our results highly reliable in this respect.

\section{CONCLUSIONS}

No significant differences in bacterial community structure ( $\alpha$ and $\beta$ diversities) were found along the different locations within the uterus. The bacterial com- 

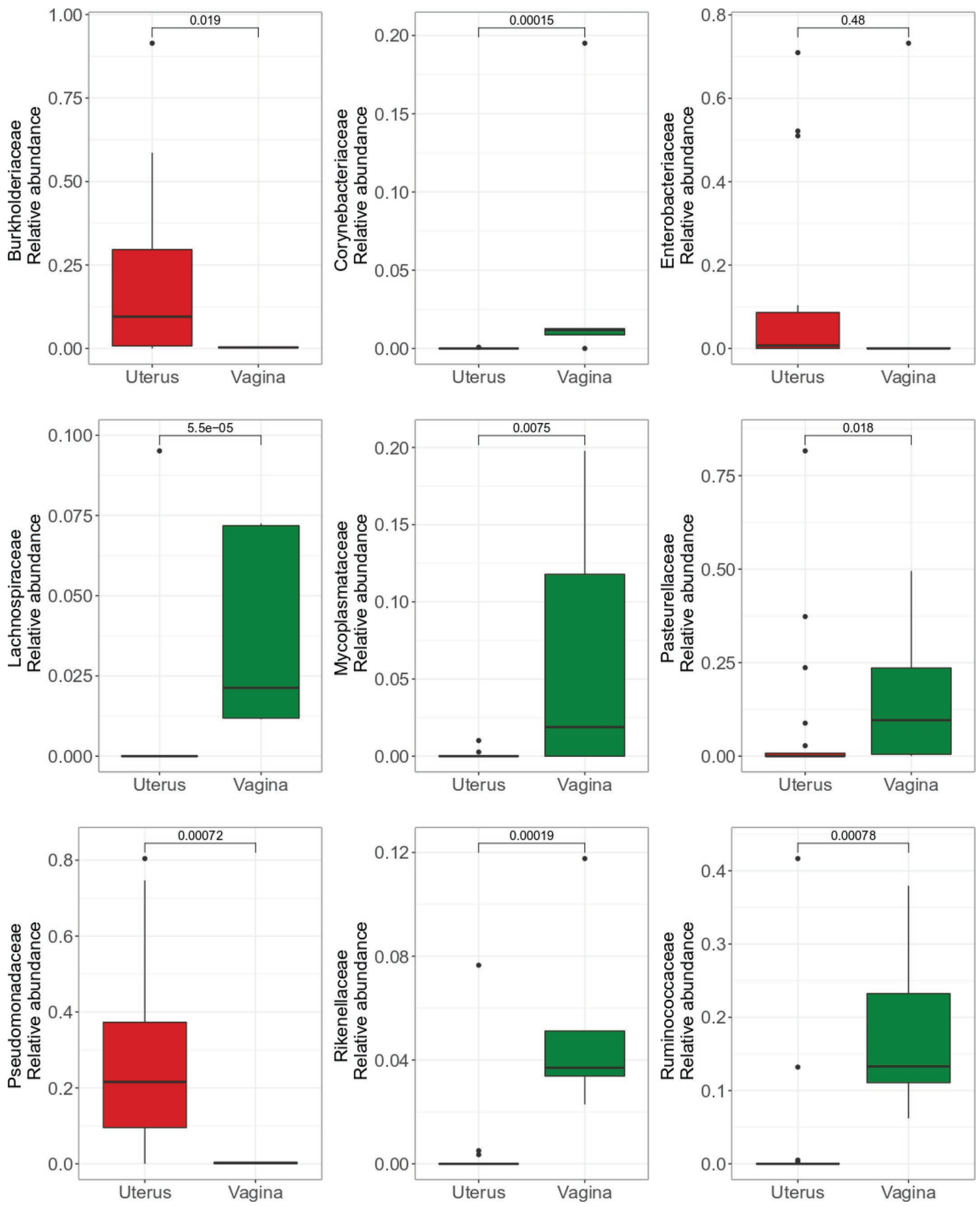

Figure 8. Box plots of the relative abundance of the most discriminating bacterial families in mid-lactation dairy cows $(\mathrm{n}=5$, decontaminated data set) in vaginal versus uterine samples. Samples were collected after the cows were killed, from the vagina and 4 different locations of the uterus (tip of the right, base of the right, tip of the left, and base of the left uterine horn). Uterine samples had greater abundance of Pseudomonadaceae and Burkholderiaceae and lesser abundance of Pasteurellaceae, Ruminococcaceae, Mycoplasmataceae, Rikenellaceae, Corynebacteriaceae, and Lachnospiraceae than vaginal samples[AU20: Please define all elements of box plots: boxes, midline, whiskers, dots.]. 

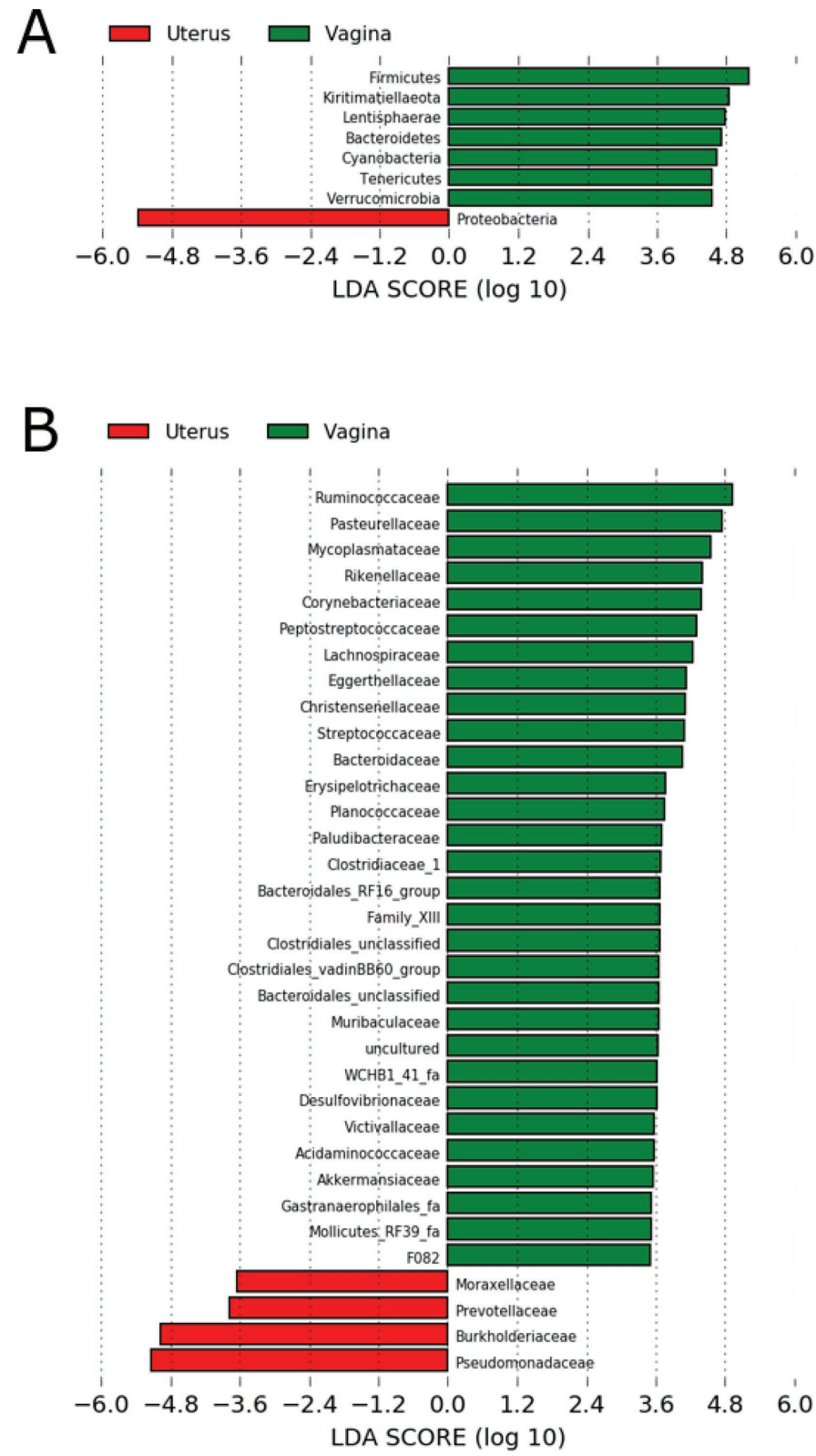

Figure 9. Linear discriminant analysis (LDA) effect size ( $\alpha$ of 0.05 and effect size threshold of 3.5) indicating differences in abundance of bacterial communities in the reproductive tract of mid-lactation dairy cows $(\mathrm{n}=5$, decontaminated data set). Samples were collected after the cows were killed, from the vagina and 4 different locations of the uterus (tip of the right, base of the right, tip of the left, and base of the left uterine horn). Key bacterial phyla (A) and families (B) were identified as differentiating between uterus and vagina.

position was different between the vagina and uterus. At the phylum level, uterine samples had a greater relative abundance of Proteobacteria, and a lesser relative abundance of Firmicutes than vaginal samples. The mid-lactation bovine genital tract is a low microbial biomass environment, which makes it difficult to dis- tinguish between its constitutive or contaminant microbiome. Microbiome exploration of such low microbial biomass environments should thus be approached with caution. The integration of key controls, according to the RIDE checklist, is necessary to decrease the effect of accidentally introduced contaminant sequences and improve the reliability of results in samples with low microbial biomass.

\section{ACKNOWLEDGMENTS}

We thank Jana De Bodt[AU15: Add affiliations for each person.], Bart Leemans and Kirsten Proost for expert technical assistance. This research was supported by a doctoral scholarship from the Special Research Fund (BOF) of Ghent University, granted to Leen Lietaer (project number 01D26917). Tim Lacoere was supported by the project of Geconcerteerde Onderzoeksactie (GOA) of Ghent University (BOF15/GOA/006). Osvaldo Bogado Pascottini was granted by Fonds voor Wetenschappelijk Onderzoek-Vlaanderen (FWO, Research Foundation, Flanders) under project number $12 \mathrm{Y} 5220 \mathrm{~N}$. The authors declare no conflicts of interest.

\section{REFERENCES}

Alipour, M. J., J. Jalanka, T. Pessa-Morikawa, T. Kokkonen, R. Satokari, U. Hynonen, A. Iivanainen, and M. Niku. 2018. The composition of the perinatal intestinal microbiota in cattle. Sci. Rep. 8:10437. https://doi.org/10.1038/s41598-018-28733-y.

Ault, T. B., B. A. Clemmons, S. T. Reese, F. G. Dantas, G. A. Franco, T. P. L. Smith, J. L. Edwards, P. R. Myer, and K. G. Pohler. 2019a. Uterine and vaginal bacterial community diversity prior to artificial insemination between pregnant and nonpregnant postpartum cows. J. Anim. Sci. 97:4298-4304. https://doi.org/10 $.1093 /$ jas $/$ skz210.

Ault, T. B., B. A. Clemmons, S. T. Reese, F. G. Dantas, G. A. Franco, T. P. L. Smith, J. L. Edwards, P. R. Myer, and K. G. Pohler. 2019b. Bacterial taxonomic composition of the postpartum cow uterus and vagina prior to artificial insemination. J. Anim. Sci. 97:4305-4313. https://doi.org/10.1093/jas/skz212.

Baker, J. M., D. M. Chase, and M. M. Herbst-Kralovetz. 2018. Uterine microbiota: Residents, tourists, or invaders? Front. Immunol. 9:208. https://doi.org/10.3389/fimmu.2018.00208.

Bakke, I., P. De Schryver, N. Boon, and O. Vadstein. 2011. PCR-based community structure studies of Bacteria associated with eukaryotic organisms: A simple PCR strategy to avoid co-amplification of eukaryotic DNA. J. Microbiol. Methods 84:349-351. https://doi .org/10.1016/j.mimet.2010.12.015.

Bogado Pascottini, O., M. Hostens, P. Dini, J. Vandepitte, R. Ducatelle, and G. Opsomer. 2016. Distribution of inflammation and association between active and chronic alterations within the endometrium of dairy cows. Reprod. Domest. Anim. 51:751-757. https://doi.org/10.1111/rda.12742.

Butain, B. J., and R. M. Nakamura. 1977. Bacteriologic studies of bovine genital tracts: The use of dye as an indicator of postmortem contamination of the uterus by vaginal fluids. Theriogenology 7:89-93. https://doi.org/10.1016/S0093-691X(77)80007-1.

Chen, C., X. Song, W. Wei, H. Zhong, J. Dai, Z. Lan, F. Li, X. Yu, Q. Feng, Z. Wang, H. Xie, X. Chen, C. Zeng, B. Wen, L. Zeng, H. Du, H. Tang, C. Xu, Y. Xia, H. Xia, H. Yang, J. Wang, J. Wang, L. Madsen, S. Brix, K. Kristiansen, X. Xu, J. Li, R. Wu, and H. Jia. 
2017. The microbiota continuum along the female reproductive tract and its relation to uterine-related diseases. Nat. Commun. 8:875. https://doi.org/10.1038/s41467-017-00901-0.

Clemmons, B. A., S. T. Reese, F. G. Dantas, G. A. Franco, T. P. L. Smith, O. I. Adeyosoye, K. G. Pohler, and P. R. Myer. 2017. Vaginal and uterine bacterial communities in postpartum lactating cows. Front. Microbiol. 8:1047. https://doi.org/10.3389/fmicb .2017.01047.

Davis, N. M., D. M. Proctor, S. P. Holmes, D. A. Relman, and B. J. Callahan. 2018. Simple statistical identification and removal of contaminant sequences in marker-gene and metagenomics data. Microbiome 6:226. https://doi.org/10.1186/s40168-018-0605-2.

de Goffau, M. C., S. Lager, U. Sovio, F. Gaccioli, E. Cook, S. J. Peacock, J. Parkhill, D. S. Charnock-Jones, and G. C. S. Smith. 2019. Human placenta has no microbiome but can contain potential pathogens. Nature 572:329-334. https://doi.org/10.1038/ s41586-019-1451-5.[AU16: A correction can be found at https: //doi.org/10.1038/s41586-019-1628-y. Please review and may changes as necessary.]

Dinno, A. 2017. dunn.test: Dunn's Test of Multiple Comparisons Using Rank Sums. R package version 1.3.5. https://CRAN.R-project .org $/$ package $=$ dunn.test.

Doughari, H. J., P. A. Ndakidemi, I. S. Human, and S. Benade. 2011. The ecology, biology and pathogenesis of Acinetobacter spp.: An overview. Microbes Environ. 26:101-112. https://doi.org/10.1264/ jsme2.ME10179.

Eisenhofer, R., J. J. Minich, C. Marotz, A. Cooper, R. Knight, and L. S. Weyrich. 2019. Contamination in low microbial biomass microbiome studies: issues and recommendations. Trends Microbiol. 27:105-117. https://doi.org/10.1016/j.tim.2018.11.003.

Franasiak, J. M., M. D. Werner, C. R. Juneau, X. Tao, J. Landis, Y. Zhan, N. R. Treff, and R. T. Scott. 2016. Endometrial microbiome at the time of embryo transfer: Next-generation sequencing of the 16S ribosomal subunit. J. Assist. Reprod. Genet. 33:129-136. https://doi.org/10.1007/s10815-015-0614-z.

Ghyselinck, J., S. Pfeiffer, K. Heylen, A. Sessitsch, and P. De Vos. 2013. The effect of primer choice and short read sequences on the outcome of $16 \mathrm{~S}$ rRNA gene based diversity studies. PLoS One 8:e71360. https://doi.org/10.1371/journal.pone.0071360.

Glassing, A., S. E. Dowd, S. Galandiuk, B. Davis, and R. J. Chiodini. 2016. Inherent bacterial DNA contamination of extraction and sequencing reagents may affect interpretation of microbiota in low bacterial biomass samples. Gut Pathog. 8:24. https://doi.org/10 .1186/s13099-016-0103-7.

Goodrich, J. K., S. C. Di Rienzi, A. C. Poole, O. Koren, W. A. Walters, J. G. Caporaso, R. Knight, and R. E. Ley. 2014. Conducting a microbiome study. Cell 158:250-262. https://doi.org/10.1016/j .cell.2014.06.037.

Jeon, S. J., F. Cunha, A. Vieira-Neto, R. C. Bicalho, S. Lima, M. L. Bicalho, and K. N. Galvao. 2017. Blood as a route of transmission of uterine pathogens from the gut to the uterus in cows. Microbiome 5:109. https://doi.org/10.1186/s40168-017-0328-9.

Jeon, S. J., A. Vieira-Neto, M. Gobikrushanth, R. Daetz, R. D. Mingoti, A. C. B. Parize, S. L. de Freitas, A. N. L. da Costa, R. C. Bicalho, S. Lima, K. C. Jeong, and K. N. Galvão. 2015. Uterine microbiota progression from calving until establishment of metritis in dairy cows. Appl. Environ. Microbiol. 81:6324-6332. https://doi .org/10.1128/AEM.01753-15.

Karstens, L., M. Asquith, S. Davin, D. Fair, W. T. Gregory, A. J. Wolfe, J. Braun, and S. McWeeney. 2019. Controlling for contaminants in low-biomass $16 \mathrm{~S}$ rRNA gene sequencing experiments. mSystems 4:e00290-19. https://doi.org/10.1128/mSystems.00290 -19 .

Karstrup, C. C., K. Klitgaard, T. K. Jensen, J. S. Agerholm, and H. G. Pedersen. 2017. Presence of bacteria in the endometrium and placentomes of pregnant cows. Theriogenology 99:41-47. https:// doi.org/10.1016/j.theriogenology.2017.05.013.

Klein-Jöbstl, D., N. M. Quijada, M. Dzieciol, B. Feldbacher, M. Wagner, M. Drillich, S. Schmitz-Esser, and E. Mann. 2019. Microbiota of newborn calves and their mothers reveals possible transfer routes for newborn calves' gastrointestinal microbiota. PLoS One 14:e0220554. https://doi.org/10.1371/journal.pone.0220554.

Knudsen, L. R. V., C. C. Karstrup, H. G. Pedersen, O. Angen, J. S. Agerholm, E. L. Rasmussen, T. K. Jensen, and K. Klitgaard. 2016. An investigation of the microbiota in uterine flush samples and endometrial biopsies from dairy cows during the first 7 weeks postpartum. Theriogenology 86:642-650. https://doi.org/10.1016/ j.theriogenology.2016.02.016.

Kozich, J. J., S. L. Westcott, N. T. Baxter, S. K. Highlander, and P. D. Schloss. 2013. Development of a dual-index sequencing strategy and curation pipeline for analyzing amplicon sequence data on the MiSeq Illumina sequencing platform. Appl. Environ. Microbiol. 79:5112-5120. https://doi.org/10.1128/AEM.01043-13.

Kunz, G., D. Beil, H. Deiniger, A. Einspanier, G. Mall, and G. Leyendecker. 1997. The uterine peristaltic pump. Pages $267-277$ in The Fate of the Male Germ Cell. Vol 424. R. Ivell, and A. F. Holstein, ed. Springer.

Laguardia-Nascimento, M., K. M. G. R. Branco, M. R. Gasparini, S. Giannattasio-Ferraz, L. R. Leite, F. M. G. Araujo, A. C. de Matos Salim, J. R. Nicoli, G. C. de Oliveira, and E. F. Barbosa-Stancioli. 2015. Vaginal microbiome characterization of nellore cattle using metagenomic analysis. PLoS One 10:e0143294. https://doi.org/10 .1371/journal.pone.0143294.

Lahti, L., S. A. Shetty, et al. 2017. Tools for microbiome analysis in R. Version 2.1.26. http://microbiome.github.io/tutorials.[AU17: Please provide complete list of authors.]

Lauder, A. P., A. M. Roche, S. Sherrill-Mix, A. Bailey, A. L. Laughlin, K. Bittinger, R. Leite, M. A. Elovitz, S. Parry, and F. D. Bushman. 2016. Comparison of placental samples with contamination controls does not provide evidence for a distinct placenta microbiota. Microbiome 4:29. https://doi.org/10.1186/s40168-016-0172-3.

Li, R., H. M. Tun, M. Jahan, Z. Zhang, A. Kumar, W. G. Dilantha Fernando, A. Farenhorst, and E. Khafipour. 2017. Comparison of DNA-, PMA-, and RNA-based 16S rRNA Illumina sequencing for detection of live bacteria in water. Sci. Rep. 7:5752. https://doi .org/10.1038/s41598-017-02516-3.

McMurdie, P. J., and S. Holmes. 2013. Phyloseq: An R Package for reproducible interactive analysis and graphics of microbiome census data. PLoS One 8:e61217. https://doi.org/10.1371/journal.pone 0061217.

Miranda-CasoLuengo, R., J. Lu, E. J. Williams, A. A. Miranda-CasoLuengo, S. D. Carrington, A. C. O. Evans, and W. G. Meijer. 2019. Delayed differentiation of vaginal and uterine microbiomes in dairy cows developing postpartum endometritis. PLoS One 14:e0200974. https://doi.org/10.1371/journal.pone.0200974.

Moore, S. G., A. C. Ericsson, S. E. Poock, P. Melendez, and M. C. Lucy. 2017. Hot topic: $16 \mathrm{~S}$ rRNA gene sequencing reveals the microbiome of the virgin and pregnant bovine uterus. J. Dairy Sci. 100:4953-4960. https://doi.org/10.3168/jds.2017-12592.

O'Callaghan, J. L., R. Turner, M. Dekker Nitert, H. L. Barrett, V. Clifton, and E. S. Pelzer. 2020. Re-assessing microbiomes in the low-biomass reproductive niche. BJOG 127:147-158. https://doi .org/10.1111/1471-0528.15974.

Oksanen, J., F. G. Blanchet, M. Friendly, R. Kindt, P. Legendre, D. McGlinn, P. R. Minchin, R. B. O'Hara, G. L. Simpson, P. Solymos, M. H. H. Stevens, E. Szoecs, and H. Wagner. 2019. Vegan: Community Ecology Package. $\mathrm{R}$ package version 2.5-6. https:// CRAN.R-project.org/package= vegan.

Perez-Muñoz, M. E., M. C. Arrieta, A. E. Ramer-Tait, and J. Walter. 2017. A critical assessment of the "sterile womb" and "in utero colonization" hypotheses: implications for research on the pioneer infant microbiome. Microbiome 5:48. https://doi.org/10.1186/ s40168-017-0268-4.

Pollock, J., L. Glendinning, T. Wisedchanwet, and M. Watson. 2018. The madness of microbiome: Attempting to find consensus "best practice" for $16 \mathrm{~S}$ microbiome studies. Appl. Environ. Microbiol. 84:e2627-17. https://doi.org/10.1128/AEM.02627-17.

Pothmann, H., J. Müller, I. Pothmann, A. Tichy, and M. Drillich. 2019. Reproducibility of endometrial cytology using cytobrush technique and agreement for the diagnosis of subclinical endome- 
tritis between five predefined endometrial sites. Reprod. Domest. Anim. 54:350-357. https://doi.org/10.1111/rda.13367.

Props, R., F. M. Kerckhof, P. Rubbens, J. De Vrieze, E. HernandezSanabria, W. Waegeman, P. Monsieurs, F. Hammes, and N. Boon. 2017. Absolute quantification of microbial taxon abundances. ISME J. 11:584-587. https://doi.org/10.1038/ismej.2016.117.

Ritchie, M. E., B. Phipson, D. Wu, Y. Hu, C. W. Law, W. Shi, and G. K. Smyth. 2015. limma powers differential expression analyses for RNA-sequencing and microarray studies. Nucleic Acids Res. 43:e47. https://doi.org/10.1093/nar/gkv007.

Rognes, T., T. Flouri, B. Nichols, C. Quince, and F. Mahé. 2016. VSEARCH: A versatile open source tool for metagenomics. PeerJ 4:e2584. https://doi.org/10.7717/peerj.2584.

Santos, T. M. A., and R. C. Bicalho. 2012. Diversity and succession of bacterial communities in the uterine fluid of postpartum metritic, endometritic and healthy dairy cows. PLoS One 7:e53048. https:/ /doi.org/10.1371/journal.pone.0053048.

Schloss, P. D., and S. L. Westcott. 2011. Assessing and improving methods used in operational taxonomic unit-based approaches for 16S rRNA gene sequence analysis. Appl. Environ. Microbiol. 77:3219-3226. https://doi.org/10.1128/AEM.02810-10.

Schloss, P. D., S. L. Westcott, T. Ryabin, J. R. Hall, M. Hartmann, E. B. Hollister, R. A. Lesniewski, B. B. Oakley, D. H. Parks, C. J. Robinson, J. W. Sahl, B. Stres, G. G. Thallinger, D. J. Van Horn, and C. F. Weber. 2009. Introducing MOTHUR: open-source, platform-independent, community-supported software for describing and comparing microbial communities. Appl. Environ. Microbiol. 75:7537-7541. https://doi.org/10.1128/AEM.01541-09.

Schoenmakers, S., R. Steegers-Theunissen, and M. Faas. 2019. The matter of the reproductive microbiome. Obstet. Med. 12:107-115. https://doi.org/10.1177/1753495X18775899.

Seferovic, M. D., R. M. Pace, M. Carroll, B. Belfort, A. M. Major, D. M. Chu, D. A. Racusin, E. C. C. Castro, K. L. Muldrew, J. Versalovic, and K. M. Aagaard. 2019. Visualization of microbes by $16 \mathrm{~S}$ in situ hybridization in term and preterm placentas without intraamniotic infection. Am. J. Obstet. Gynecol. 221:146.e1-146. e23. https://doi.org/10.1016/j.ajog.2019.04.036.[AU18: An erratum can be found at https://doi.org/10.1016/j.ajog.2019.08 .012. Please review and make changes as needed.]

Segata, N., J. Izard, L. Waldron, D. Gevers, L. Miropolsky, W. S. Garrett, and C. Huttenhower. 2011. Metagenomic biomarker discovery and explanation. Genome Biol. 12:R60. https://doi.org/10.1186/ gb-2011-12-6-r60.
Sheldon, I. M., J. Cronin, L. Goetze, G. Donofrio, and H. J. Schuberth. 2009. Defining postpartum uterine disease and the mechanisms of infection and immunity in the female reproductive tract in cattle. Biol. Reprod. 81:1025-1032. https://doi.org/10.1095/biolreprod .109.077370.

Sisti, G., T. Kanninen, and S. Witkin. 2016. Maternal immunity and pregnancy outcome: Focus on preconception and autophagy. Genes Immun. 17:1-7. https://doi.org/10.1038/gene.2015.57.

Spilker, K.-C., J. Sielhorst, G. Martinsson, S. Pricking, W. Hassler, R. Böse, K. Rohn, and H. Sieme. 2017. Accuracy of different endometrial swabbing techniques in the mare. Pferdeheilkunde 33:172178. https://doi.org/10.21836/PEM20170210.

Swartz, J. D., M. Lachman, K. Westveer, T. O'Neill, T. Geary, R. W. Kott, J. G. Berardinelli, P. G. Hatfield, J. M. Thomson, A. Roberts, and C. J. Yeoman. 2014. Characterization of the vaginal microbiota of ewes and cows reveals a unique microbiota with low levels of lactobacilli and near-neutral pH. Front. Vet. Sci. 1:19. https://doi.org/10.3389/fvets.2014.00019.

Täte, M. 2011. Kulturelle sowie 16S rDNA basierte Untersuchungen der aeroben und anaeroben Keimflora des equinen Uterus. PhD Thesis. Institute for Reproductive Medicine, University of Veterinary Medicine Hannover.

Theis, K. R., R. Romero, A. D. Winters, J. M. Greenberg, N. GomezLopez, A. Alhousseini, J. Bieda, E. Maymon, P. Pacora, J. M Fettweis, G. A. Buck, K. K. Jefferson, J. F. Strauss, O. Erez, and S. S. Hassan. 2019. Does the human placenta delivered at term have a microbiota? Results of cultivation, quantitative real-time PCR, 16S rRNA gene sequencing, and metagenomics. Am. J. Obstet. Gynecol. 220:267.e1-267.e39. https://doi.org/10.1016/j.ajog .2018.10.018.

Vandeputte, D., G. Kathagen, K. D'hoe, S. Vieira-Silva, M. Valles-Colomer, J. Sabino, J. Wang, R. Y. Tito, L. De Commer, Y. Darzi, S. Vermeire, G. Falony, and J. Raes. 2017. Quantitative microbiome profiling links gut community variation to microbial load. Nature 551:507-511. https://doi.org/10.1038/nature24460.

Verstraelen, H., R. Vilchez-Vargas, F. Desimpel, R. Jauregui, N. Vankeirsbilck, S. Weyers, R. Verhelst, P. De Sutter, D. H. Pieper, and T. Van De Wiele. 2016. Characterisation of the human uterine microbiome in non-pregnant women through deep sequencing of the V1-2 region of the $16 \mathrm{~S}$ rRNA gene. PeerJ 4:e1602. https://doi .org/10.7717/peerj.1602.

Wickham, H. 2010. A layered grammar of graphics. J. Comput. Graph. Stat. 19:3-28. https://doi.org/10.1198/jcgs.2009.07098. 